\title{
STUDIES ON ABDOMINAL ULTRASONOGRAPHY IN ARABIAN HORSES
}

\author{
NASR, M.Y.; FADEL, M.S. ${ }^{* *}$; NOHA, A. BEDER ${ }^{*}$ and ELZANATY, A.S. \\ *Anim. Medicine Dept., Fac. of Vet. Medicine, Damanhur Univ. \\ **Animal Reproduction Res. Instit., Egypt. \\ Email: moh_ye@yahoo.com
}

\section{ABSTRACT}

Received at: 17/8/2014

Accepted: 27/9/2014
Eighteen female Arabian horses, of 3-5 years old were examined ultrasonographically on the abdomen without clipping the hair, but with soaking hair with isopropyl alcohol to improve contact. The stomach was scanned from the left side between the $8^{\text {th }}$ or $9^{\text {th }}-12^{\text {th }}$ or $13^{\text {th }}$ inter-costal spaces (ICS). The duodenum was examined from the right flank at the $16^{\text {th }}$ and $17^{\text {th }}$ ICS immediately ventral to the kidney. Jejunum is not usually imaginable. The cecum was imaged along the body wall in the dorsal and caudal portions of the right abdomen. Large colon was normally visible throughout the majority of the abdomen along both body wall and the ventral abdomen. The small colon was scanned dorsal to the left ventral colon (LVC). The liver was scanned ventral to the margins of the lung along the right side of the abdomen from $6^{\text {th }}-15^{\text {th }}$ ICS and along the left side of the cranial ventral abdomen from $6^{\text {th }}-9^{\text {th }}$ ICS. The spleen was scanned along the left side of the abdomen adjacent to the body wall from the $8^{\text {th }}$ or $9^{\text {th }}$ ICS to the $17^{\text {th }}$ ICS. The right kidney was scanned from the $14^{\text {th }}-17^{\text {th }}$ ICS. The left kidney was scanned in the $17^{\text {th }}$ ICS and para-lumbar fossa. The urinary bladder was imaged trans-rectally.

Key words: Arabian horses, Abdomen, Ultrasonography.

\section{INTRODUCTION}

Arabian horse historically has maintained a reputation as the horse of beauty, intelligence, courage, endurance, and romance. It is gentle, affectionate, and familiar, almost to the point of being troublesome. (AHA web site, 2013). Arabian horses have 5 lumbar vertebrae instead of the usual 6 and 17 pairs of ribs rather than 18 in other breeds (Edwards, 1973).

Ultrasonography is a non-invasive real-time imaging modality, with minimal potential complication, and it was quickly recognized as an invaluable aid to diagnostic imaging in the horses. There are now many potential applications, including abdominal ultrasonograghy. The large size of the structures relatively inaccessible to other diagnostic techniques, such as radiography and endoscopy. Laparoscopy is valuable diagnostic tool, although the expertise and equipment required restrict its availability to specialist centers (Freeman, 2003).

Since the introduction of diagnostic ultrasonography to veterinary medicine in the 1970 , it has had increasingly wide application (Rantanen, 1986). The practical part of the ultrasound examination is that it can be quickly performed immediately following the physical examination (Fairfield, 2011).
Ultrasonography allows for rapid and non-invasive examination of portions of the abdominal viscera, some of which cannot be examined by any other method. Ultrasonography also allows some assessment to be made of intestinal activity and lumen contents (Freeman, 2001).

Aim of the work to encourage ultrasound use as a routine procedure in the examination of intraabdominal structures in Arabian horses and to establish a stander reference for the appearance of normal intra-abdominal structures images by ultrasound in Arabian horses.

\section{MATERIALS and METHODS}

Eighteen female Arabian horses of 3-5 year old were clinically healthy obtained from Animal Reproduction Research Institute, Egypt from March 2013-May 2014. On admission to the hospital, each horse had a wide set of observation including a complete history and thorough physical examination (Orsini et al., 1988). Rectal examination, body temperature, respiratory and pulse rates, conjunctival membrane, superficial lymph nodes and auscultation of intestinal sound were preformed. Fecal sample was collected from the rectum of each horse for physical examination; consistency, color, odor and 
presence of blood, mucus or gross parasite (Taylor and Hillyer, 1997).

Also a direct smear method was used for parasitological examination (Ewing, 1974). Flotation or sedimentation method was used for detection of nematodes (ascaris, strongyloides, trichostronyles) and some tapeworms (Kelly, 1974). Fecal sand can be detected using a simple test (Merritt and Colahan, 1992). Two blood samples were collected from all examined horses by jugular vein puncture, the first sample for packed cell volume (PCV \%), total erythrocyte count (TEC million/cu $\mathrm{mm}$ ) and hemoglobin concentration $(\mathrm{Hb} \mathrm{g} / \mathrm{dl})$. The second sample for determination of blood urea nitrogen
(BUN), creatinine $(\mathrm{mg} / \mathrm{dl})$, aspratataminotransferase (AST) and gamma glutamyltranspeptidase (GGT). (iu/ml) (Reitman and Frankle, 1957) and (Tietz, 1990). (Frank Taylor et al., 2010).

Abdominal US was the principal examination protocol of examined horses; an ultrasound scanner (EXAGYNE) with a micro convex probe 3.5-5 $\mathrm{MHz}$ and a linear array probe 6-8 $\mathrm{MHz}$ (Fig.1). Ultrasonographic coupling gel (SGMOSCAN, SGMO Chemical Industry, Egypt) was used. Two techniques for ultrasonographic examination were used, the first technique is trans-cutaneous (trans-abdominal) US (Abutarbush, 2006 and Fairfield Bain, 2011). The second technique is trans-rectal US (Freeman, 2002).
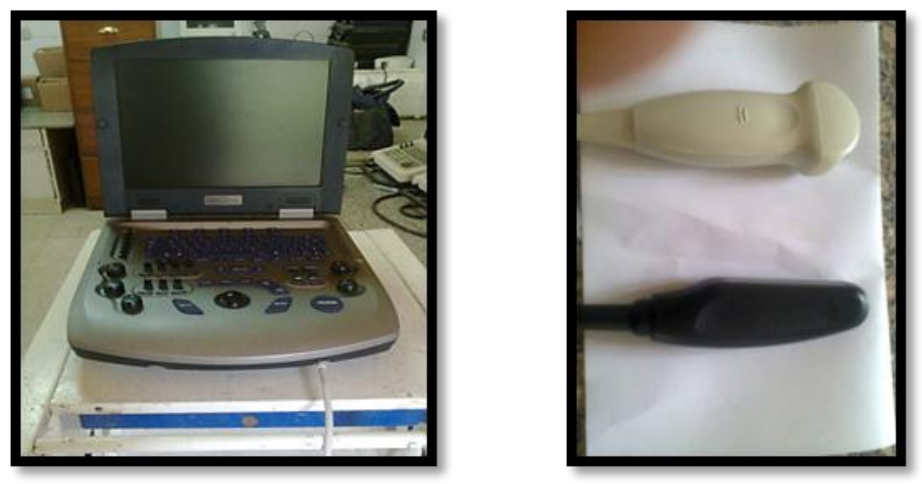

Fig. 1: An ultrasound machine (EXAGYN ECM company, France) (the left). A micro convex probe 3.5-5 MHz and a linear array probe 6-8 $\mathrm{MHz}$ (the right).

The stomach was scanned medial to the spleen in the cranial and mid portion of the left side of the abdomen between the $8^{\text {th }}$ or $9^{\text {th }}$ to $12^{\text {th }}$ or $13^{\text {th }}$ ICS (Scharner et al., 2002). The duodenum was examined along the right flank accessible to trans-cutaneous US at the $16^{\text {th }}$ and $17^{\text {th }}$ ICS immediately ventral to the kidney (Klohnen et al., 1996). Jejunum is not usually imaginable in the adult horse owing to the interposed large colon (Worth, 1995).

The cecum was imaged along the body wall in the dorsal and caudal portions of the right abdomen (Reef, 1998) (Fig.2).
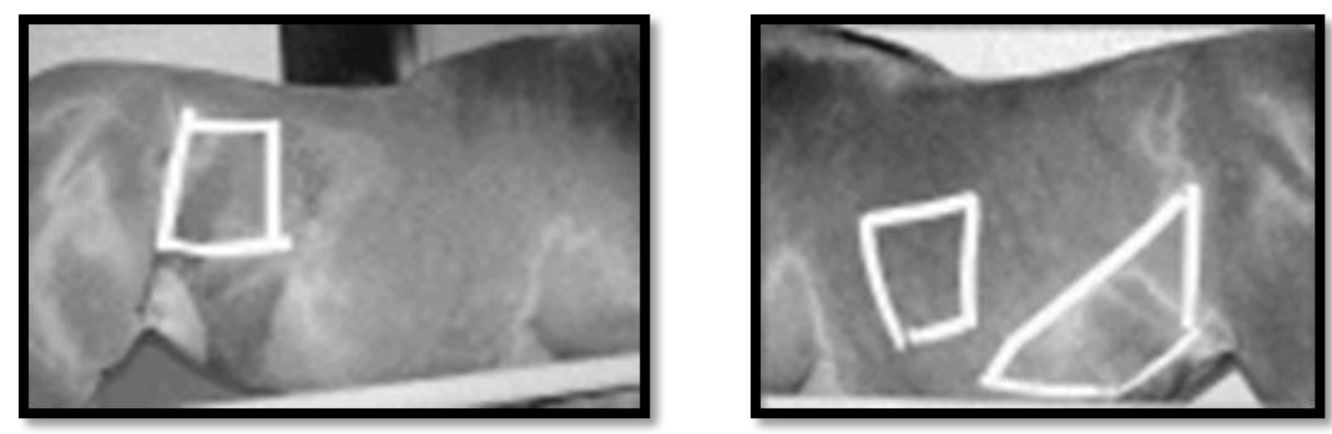

Fig. 2: Illustration of the land marks on the right and left sides of a horse used for US evaluation of the base of the cecum (right), stomach and LVC (left) (Abutarbush, 2006). 
Large colon was normally visible throughout the majority of the abdomen along both body walls on the ventral abdomen according to Jones et al. (2003). The small colon was scanned dorsal to the urinary bladder from the ventral abdomen if the bladder is full and adjacent to body wall (Byars and Halley, 1986 and Reef, 1998).

The liver was scanned ventral to the margins of the lungs along the right side of the abdomen from the $6^{\text {th }}-15^{\text {th }}$ ICS and along the left side of the cranial ventral abdomen from the $6^{\text {th }}-9^{\text {th }}$ ICS (Rantanen, 1986). The spleen was scanned along the left side of the abdomen adjacent to the body wall from the $8^{\text {th }}$ or $9^{\text {th }}$ ICS to the $17^{\text {th }}$ ICS. The spleen was scanned in adorsal, sagittal and transverse plan (Reef, 1998).

Ultrasonographic scanning of the kidneys was performed from the left and right body walls; the right kidney was scanned from the $14^{\text {th }}-17^{\text {th }}$ ICS using a 3.5 MHZ transducer, while the left kidney was scanned in the $17^{\text {th }}$ ICS and para-lumbar fossa. Scanning was performed in both sagittal and transverse plans (Hoffman et al., 1995). The urinary bladder was imaged trans-rectally, transverse, sagittal or combination of both was obtained. Also transabdominal ultrasonographic examination from the ventral abdominal window is performed, if it distended (Yamaga and Too, 1984).

Statistical analysis: Comparisons were made by using repeated measures ANOVA between all mean values of obtained parameters in all groups.
Significance was set at $\mathrm{p} \leq 0.05$. Measurements are reported as the mean value $\left(\mathrm{X}^{-}\right) \pm$the standard error of the mean (Sx-) (Heiman, 1992).

\section{RESULTS}

Normal clinical findings were recorded; mean body temperature was $37.5 \pm 0.10^{\circ} \mathrm{C}$. respiratory and pulse rates were $12 \pm 0.60$ /one min. and $30 \pm 1.1 \mathrm{~b} /$ one min. respectively. Other investigations including conjunctival membranes, eye capillaries, intestinal sound and rectal findings were normal. Fecal examination; parasites, sand, blood....etc. revealed negative results. PCV, TEC and Hb were $39.0 \pm 2.71$ $\%, 6.43 \pm 0.50 \mathrm{million} / \mathrm{cu} \mathrm{mm}$ and $14.9 \pm 0.59 \%$. respectively. Liver and renal function tests were within normal levels; AST activity (118.0 $\pm 9.2 \mathrm{u} / \mathrm{l}$.), GGT activity (15.0 $\pm 1.18 \mathrm{u} / \mathrm{l}$.), BUN (20.9 \pm 1.64 $\mathrm{mg} / \mathrm{dl})$, creatinine $(1.2 \pm 0.04 \mathrm{mg} / \mathrm{dl})$ were obtained.

Ultrasonographical examination of the stomach, showed that the wall of the greater curvature was identified as a curved hyper-echoic line adjacent to the spleen deeply to it, between the $9^{\text {th }}-13^{\text {th }}$ ICS at the level of the shoulder (Fig. 3). Spleen is immediately adjacent to the body wall of the left side ventrally at $8^{\text {th }}$ ICS to the para-lumbar fossa (Fig.3\&8). The spleen's ultrasonsgraphic architecture is usually homogenous with splenic vein in it's medium. The echogenicity of the spleen is greater than that of the liver or kidneys.

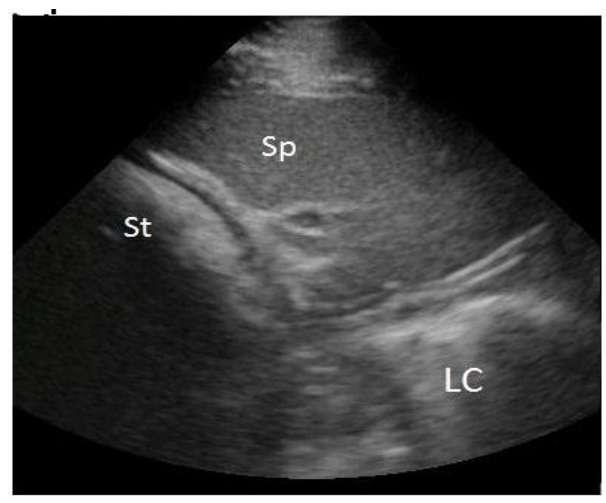

Fig. 3: Images of stomach (St), spleen (Sp), and left ventral colon (LVC) was obtained from the left restoral abdomen.

Right Kidney located in restoral right para-lumbar fossa to $16^{\text {th }} \mathrm{ICS}$, it's length $13-18 \mathrm{Cm}$ in transverse plane and 13-15 Cm in dorsal plane (Fig.4). The left kidney lies ventral to the last rib and first 2 or 3 lumbar transverse processes (Fig. 5). The duodenum is located ventral to the right kidney correspond to a line drawn from the olecranon to the tuber sacrale between the $13^{\text {th }}-17^{\text {th }}$ ICS (Fig.4,6). The duodenum appeared flat, duodenal wall and its contents are easily distinguishable, It had frequent contractions. 


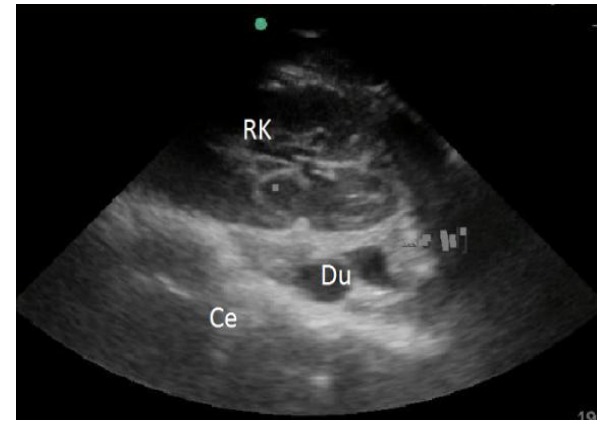

Fig. 4: Image of the right kidney (RK), (Ce) and (Du) from caudal abdomen.

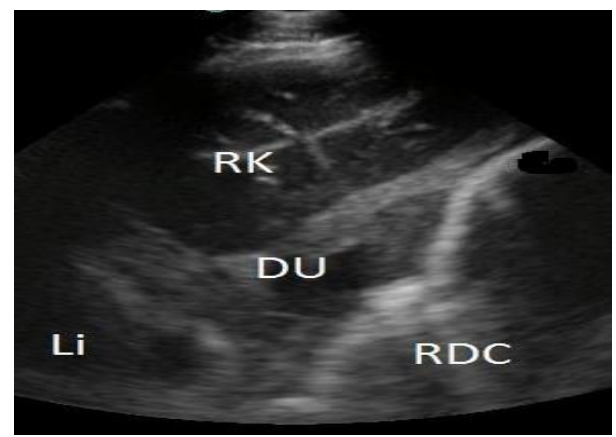

Fig. 6: Image of duodenum (Du) from the right caudal abdomen.

Ileum is hard to visualize while jejunum is usually found in the left inguinal area, medial to the spleen and the left ventral colon (Fig. 7). The left ventral colon is located ventro-medial to the spleen, identified by sacculation on its wall which measure 4 $\mathrm{mm}$. Gases in the colon give a hyper-echoic wall with an indistinct luminal border and intra-luminal acoustic shadowing that precludes identification of the contents and the medial wall. The left dorsal colon can imaged dorsal, lateral and medial to the left ventral colon, it is not sacculated (Fig. 8).

The right dorsal colon is located immediately caudal to the liver and duodenum, it has no sacculations, and

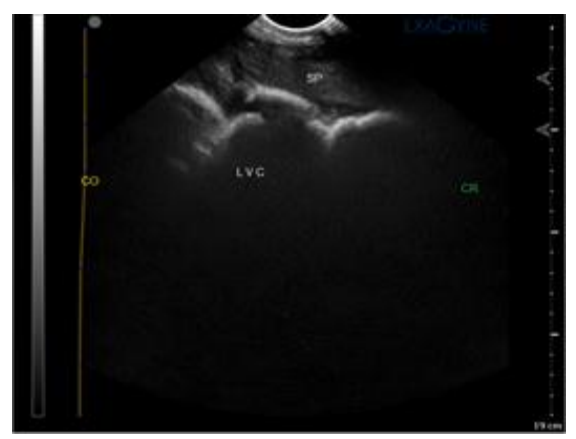

Fig.8: Image of left ventral colon (LVC) identified by its sacculations and spleen (sp).

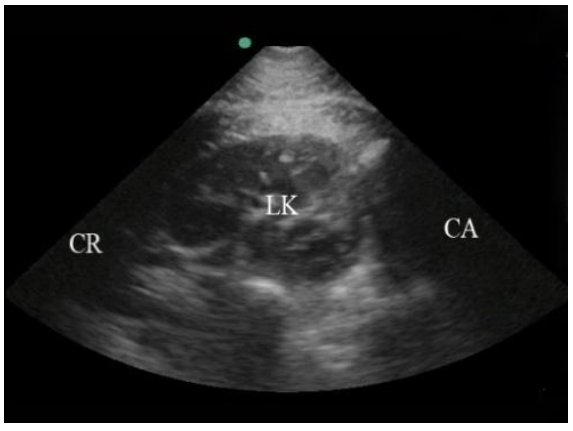

Fig. 5: Image of the left kidney from the left side of abdomen at last 2 ribs.

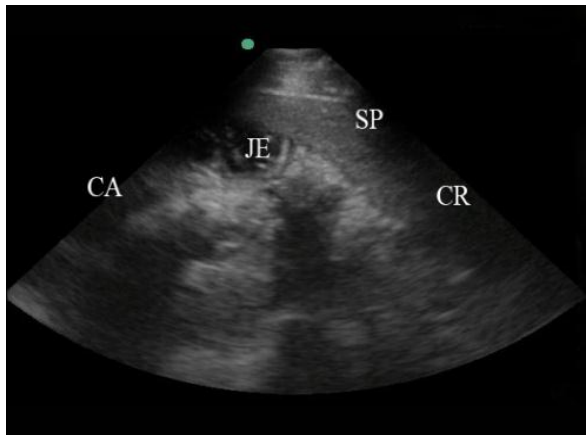

Fig. 7: Image of jejunum (JE), caudal end of the spleen (Sp) from the left inguinal area.

its wall appears as a hyper-echoic curved line adjacent to the liver. The right ventral colon is located just ventral to the right dorsal colon, it has sacculations with $<4 \mathrm{~mm}$ thinking of the wall, its contents and far wall are obscured by luminal gas (Fig. 10). Small colon is located in the left paralumbar fossa medial to/or ventral to the spleen because of its small diameter, sacculation and packed serpentine loops that suspended from the dorsal meso-colon, often only small sections of the loop surface are visible ultrasonographically as short, sharply curving, hyper-echoic lines and luminal gas prevents visualized of the contents and the distal walls

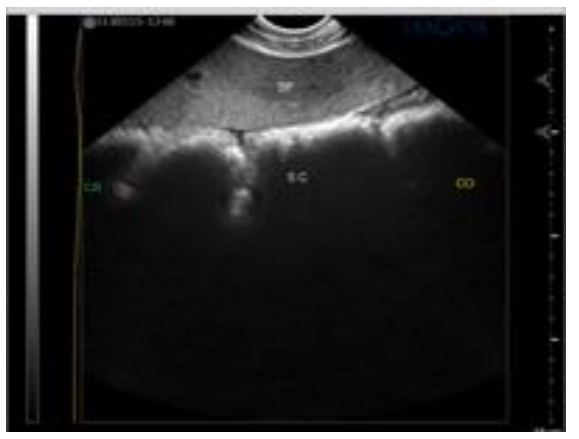

Fig.9: Image of spleen (sp) and small colon (SC) identified by its serpentine loops. 
Cecum is extended from the right para-lumbar fossa to the ventral mid line. The cecum is sacculated with $<4 \mathrm{~mm}$ wall thickness and gas in the lumen precludes imaging of the contents and far wall (Fig. 4). The liver is located on the right side at the level of the shoulder between the $6^{\text {th }}-14^{\text {th }}$ ICS and the diaphragm to RDC. The architecture of the liver is relatively homogenous; The general ecogenicity of the liver is less than that of the spleen. Portal veins have more connective tissue in their walls, so they have more echogenic walls than the hepatic veins. The smaller

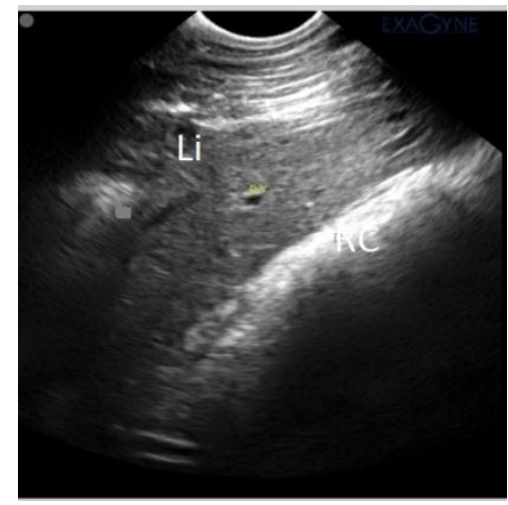

Fig. 10: Image of liver (li) and right dorsal colon (RC).

\section{DISCUSSION}

Abdominal ultrasonography in the mature horses is extremely useful in the investigation of acute intestinal problems, recurrent colic and weight loss, as well as the imaging of abdominal organs such as the liver, spleen and urogenital system (Reef, 1998). It may occasionally be used to complement other investigations of the alimentary tract however, a prerequisite for successful examination is a thorough knowledge of the normal topographical anatomy of the abdomen and the ultrasonographic appearance of organs, and both percutaneous and rectal approaches are possible, depending up on the area of interest (Frank Taylor et al., 2010). Clipping the hair is not necessary with use of iso propyl alcohol to moisten the skin and the hair, aquoes ultrasound gel give more clearance of images (Abutarbush, 2006 and Freeman, 2002). The proper preparation for transrectal ultrasound includes adequate restraint of horses. Administration of sedation is needed and use of obstetrical lubricant (Freeman, 2002).

Ultrasonographic examination of the stomach, showed it located in the left side of the abdomen deep to spleen between the $8,9^{\text {th }}$ and the $12,13^{\text {th }}$ ICS at the level of the shoulder as a curved hyperechoic line adjacent to the spleen and the gastro splinc vein, proximal to costochondral junction. This coincided with those reported by Michelle. (2011). portal veins appear as hyper-echoic parallel lines. The ventral edges of the normal liver are distinctly sharp. (Fig. 10).

The urinary bladder was easily scanned transrectally. The echogenicity of the bladder contents varied in horses, from an-echoic with hyper-echoic particles to a homogeneous pattern similar to that of the spleen (Fig.11).

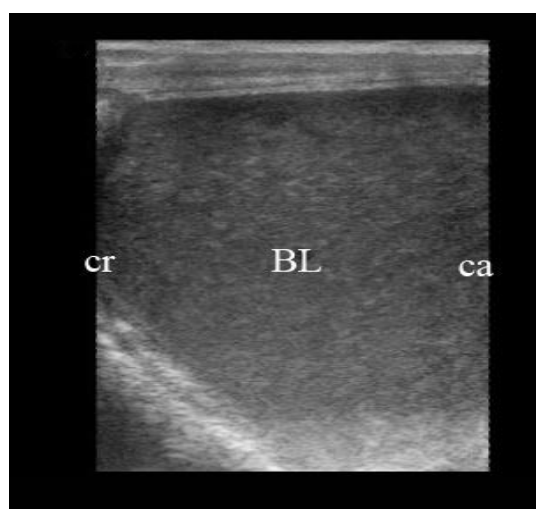

Fig. 11: Image of bladder (BL) by trans-rectal ultrasond.

The duodenum was assessed at two locations. The first was venteral to the caudal pole of the right kidney at the 16th -17 th ICSs on the right flank. It was also examined at a second location from the 12th -15 th ICSs, between the liver and the right dorsal colon. These agree with those reported by Reef (1998), Freeman (2002) and Scharner et al. (2002).

The jejunum cannot be distinguished from the ileum by ultrasound, this due to additional muscle layer of the ileac wall. It has a seven layered appearance. Loops of jejunum can be imaged in the ventral abdomen or in the more ventral parts of the left or right para-lumbar fossa. They appear as flat or triangular hyper-echoic structures with very sparse contents or hypo-echoic to echogenic with a hyperechoic echo from the mucosal surface. These agree with those reported by Mitchell et al. (2005), Freeman (2002), Scharner et al. (2002) and Worth (1995).

The caecum was identified by its location within the right caudal abdomen, its large diameter, sacculated and contracted. If trans-rectal ultrasound was used, then identification of the caecum could be confirmed by palpation of the medial caecal band. Similar findings were described by Freeman (2002) and Mitchell et al. (2005). 
The large colon was identified along the ventral and the right body wall and appeared as a hyper-echoic, slightly curvi-linear line with calculations. Because of gas contents in the colon, solid contents were not usually evident. The ventral colon had four taenial bands sacculation or haustrations, while in the left dorsal colon, there were only a taenial band on the mesenteric border in which the sacculation disappeared. The right dorsal colon had three taenial bands sacculation and the small colon located in the dorsal abdomen and reliable identification will require palpation of its smaller diameter sacculation and two mesenteric bands that the right dorsal colon could most reliably be imaged ultrasonographically at the $11^{\text {th }}, 12^{\text {th }}$ and $13^{\text {th }}$ ICS. Similar findings were described by Sharener et al. (2002), Freeman (2002), Jones et al. (2003), Mitchell et al. (2005) and Abutarbush (2006).

The liver was imaged on the right side of the abdomen, below the right lung margin, and extending from the cranio-ventral part of the abdomen to the right kidney and was recognizable by its branching vasculature with the portal and hepatic veins. The liver parenchyma was homogeneous and of medium echogenicity. This agree with these reported by Reef (1998) and Scharner et al. (2002). The spleen was imaged between dorsal and middle third of the abdomen at the level of the $17^{\text {th }}$ ICS. The splenic thickness was $5-8 \mathrm{~cm}$ tapering to a thin edge caudally. The spleen was homogeneously echogenic throughout except for infrequent small blood vessels appearing in longitudinal and cross-section views. The capsule was hyper-echogenic and the parenchyma was moderately echogenic with a finely mottled pattern. These coincided with those reported by Schmidt (1989), Reef (1998) and Valeria Busoni et al. (2011).

The right kidney in restoral right para-lumbar fossa to $16^{\text {th }}$ ICS, its length $13-18 \mathrm{~cm}$ in transverse plane and $13-15 \mathrm{~cm}$ in dorsal plane, the ureters can not be imaged Michelle (2011). The left kidney lies ventral to the last rib and first 2 or 3 lumbar transverse processes. These agree with those reported by Michelle (2011). The fibrous capsule of the kidney was evident as a hyper-echoic line forming the borders of the kidney image. The renal parenchyma was $1.0-2.5 \mathrm{~cm}$ thick in healthy horses and was less echogenic than surrounding tissue, the renal pelvis was hyper-echogenic, branches of renal arteries were evident especially in the medullary and pelvic area located deep to the cortex as an-echoic, pulsatile structures 2-3 $\mathrm{mm}$ in diameter. Similar findings were described by Schmidt (1989).

The urinary bladder was easily scanned transrectally. The bladder wall was uniformly echogenic and appeared thinner when the bladder was distended. The echogenicity of the bladder contents varied in horses, from an-echoic with hyper-echoic particles to a homogeneous pattern similar to that of the spleen. The bladder could be imaged also transcutaneously from the ventral abdomen window in many adult horses when their bladder was full and appeared an-echoic with hyper-echoic particles and/or contain hypo-echoic to echoic mucous. This agrees with Schmidt (1989) and Reef et al. (2004).

It could be concluded that a clinician's working knowledge of these elements is the key to building confidence in distinguishing normal from abnormal ultrasonographic findings in Arabian horses.

\section{REFERENCES}

Abutarbush, S.M. (2006): Use of ultrasonography to diagnose large colon volvulus in horses. J. Am. Vet. Med. Assoc., 228 (3): 409-413.

A H A. web site. (2013): "The Arabian Horse Today". Arabian Horse History \&Heritage. Arabian Horse Association. Archived from the original on 13 May 2008. Retrieved 2013-12-26.

Byars, T.D. and Halley, J. (1986): Uses of ultrasound in equine internal medicine. Vet. Clin. North. Am. Equine Pract. 2 (1): 253-258.

Edwards, G.B. (1973): Cited in Anatomy and Conformation of Arabian Horse. Dreenan Press, Ltd. ISBN 0-88376-025-8. Retrieved from Wikipedia 2013-12-9.

Ewing, S.A. (1974): Examination for parasite in coles, E.H.(ed): Veterinary Clinical Pathology, W.B. Saunders Company, London, Pp. 472-525.

Fairfield, T.B. (2011): Focus Meeting on Colic. The AAEP. Indianapolis, IN, USA- July 24-26, 2011.

Fischer, A.T. (1997): Advances in diagnostic techniques for horses with colic. Vet. Clin. North. Am. Equine Pract., 13(2): 203-219.

Frank, G.R. Taylor; Tim J. Brazil and Mark H. Hillyer (2010): Diagnostic Techniques in Equine Medicine. 2nd ed. Saunders. P 54.

Freeman, SL. (2003): Diagnostic ultrasonography of the mature equine abdomen. Equine Vet Educ; 15:319-330.

Freeman, S. (2002): Ultrasonography of the equine abdomen. Techniques and normal findings. In practice, 24(4): 204-211.

Freeman, S.L.; Boswell, J.C. and Smith, R.K. (2001): Use of trans-rectal ultrasonography to aid diagnosis of small colon stranulation in two horses. Vet. Rec.; 148(26): 812-813.

Heiman, G.W. (1992): Basic statistics for the behavior sciences. $1^{\text {st }}$ ed. Houghton Mifflin Company. Boston, USA.

Hoffman, K.L.; Wood, A.K.W. and Mc-Carthy, P.H. (1995): Sonographic-anatomic correlation and imaging protocol for the Kidneys of horses A. M. J. Vet. Res., 56(11): 1403-1412. 
Jones, S.L.; Davis, J. and Rowlingson, K. (2003): Ultrasonograghic findings in horses with right dorsal colitis: five cases (2000-2001). j.A.M. Vet. Med. Assoc., 222(9): 1248-1251.

Kelly, W.R. (1974): Veterinary Clinical Diagnosis. $2^{\text {nd }}$ ed. Bailliere Tindall. London. P. 220-350.

Klohnen, A.; Vachon, A.M. and Fischer, A.T. (1996): Use of diagnostic ultrasonography in horses with signs of acute abdominal pain. J. Am. Vet. Med. Assoc., 209 (9): 1597-1601.

Merritt, A.M. and Colahan, P.T. (1992): Abdominal pain without distension or mass. In Vetetinary Gastroentrology. $2^{\text {nd }}$ ed, Anderson, N. V. Lea and Febiger, Philadelphia. P. 603-630.

Mitchell, C.F.; Malone, E.D.; Sage, A.M. and Niksich, K. (2005): Evaluation of gastrointestinal activity patterns in healthy horses using B mod and Doppler ultrasonography. Can. Vet. J., 46(2):134-140.

Michelle, H.B. (2011): Understanding Abdominal Ultrasonography in Horses: Which Way Is Up. Compendium: Edu. Vet. Georgia. September, E1-E8.

Orsini, J.A.; Elser, A.H.; Galligan, D.T.; Donawick, W.J. and Kronfeld, D.S. (1988): Prognostic index for acute abdominal crisis (colic) in horses. Am. J. Vet. Res.; 49(11): 1969-1971.

Rantanen, N.W. (1986): Diseases of the liver. Vet. Clin. North. Am. Equine Pract.; 2(1): 104-114.

Reef, V.B. (1998): Abdominal Ultrasonography in Equine Diagnostic Ultrasound. W.B Saunders Company. Philadelphia. Pp. 273-363.

Reef, V.B.; Whittier, M. and Allam, L.G. (2004): Sonographic Evaluation of the Adult
Abdomen. Clin. Tech. Equine Pract. 3: 294-307.

Reitman, S. and Frankel, S. (1957): A colorimetric method for the determination of serum glutamic oxalacetic and glutamic pyruvic transaminases. Am. J. Clin. Path; 28 (1): 56-63.

Scharner, D.; Rotting, A.; Gerlach, K. and Freeman, D.E. (2002): Ultrasonography of The Abdomen in the Horse with colic. Clin. Tech. Equine Pract., 1(3):, 118-124.

Schmidt, A.R. (1989): Trans-rectal Ultrasonography of the Caudal Portion of Abdominal and Pelvic Cavities in Horses. J. Am. Med. Assoc., 194(3): 365-371.

Taylor and Hillyer M.H. (1997): Diagnostic Techniques in Equine Medicine W. B. Saunders ltd. London. Pp. 19-63.

Tietz, N.W. (1990): Clinical Guide to Laboratory Test: Colorimetric Methods for detection of BUN $2^{\text {nd }}$ ed. Philadelphia, W., B. Saunders: 566-575.

Valeria Busoni; Virginie De Busscher; Diego Lopez; Denis Verwilghen and Dominique Cassart. (2011): Evaluation of a protocol for fast localized abdominal sonography of horses (FLASH) admitted for colic. The Veterinary Journal 188: 77-82.

Worth, L.T. (1995): Ultrasonography of normal equine small intestine (abstract). Vet. Radiol. and ultrasound; 36(4): 351-364.

Yamaga, $Y$. and Too, K. (1948): Diagnostic ultrasound imaging in domestic animals. Fundamental studies on abdominal organs and fetuses. Jpn. J. Vet. Sci; 46(2): 203-212.

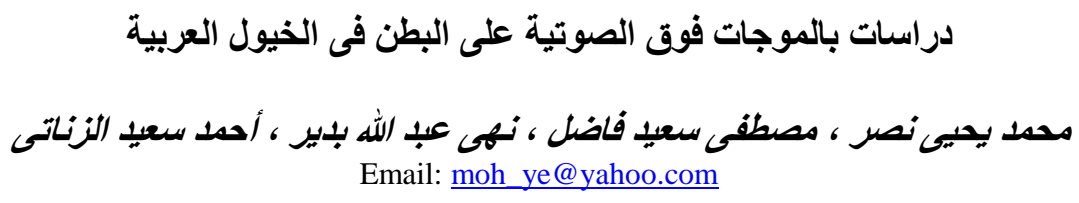

أجريت در اسة على عدد ه 1 خيل عربى واردة لمستشفى معهد بحوث التناسليات الحيو انية بالهرم، وكانت كل الحيو انات محل الدراسة

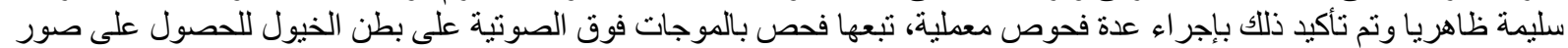

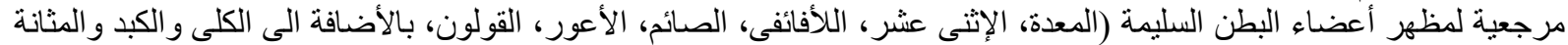
البولية و الطحال) تمهيدا لإستخدام الموجات فوق الصونية كوسيلة تشخيصية روتينية لإمر اض البطن فى الخيول العربية بمصر. 